\title{
In vitro study on the antioxidant activity of methanolic leaf extract of Carica papaya
}

\author{
Haseena K. Aboobacker', Gopesh Valoth ${ }^{1 *}$, Sabeena Kizhedath ${ }^{2}$
}

${ }^{1}$ Department of Pharmacology, Govt. Medical College Thrissur, Kerala, India

${ }^{2}$ Department of Pharmacology, Govt. Medical College, Manjeri, Kerala, India

Received: 03 March 2020

Accepted: 19 March 2020

*Correspondence:

Dr. Gopesh Valoth,

Email: drgopeshvaloth@gmail.com

Copyright: $@$ the author(s), publisher and licensee Medip Academy. This is an open-access article distributed under the terms of the Creative Commons Attribution Non-Commercial License, which permits unrestricted non-commercial use, distribution, and reproduction in any medium, provided the original work is properly cited.

\begin{abstract}
Background: Newer drug research worldwide is now focusing on medicinal plants for ensuring health and vitality due to the seemingly safer side effect profile and abundance of plants in nature, compared to synthetic drugs. Antioxidants are vital in preventing free radical induced tissue damage. The purpose of the present study is to evaluate the antioxidant activity of the methanolic extract of the leaves of Carica papaya using 1,1-diphenyl-2picrylhydrazine (DPPH). Phytochemical tests proved the presence of bioactive ingredients in the extract.

Methods: DPPH free radical assay, one of the most accurate methods for evaluating antioxidant activity, was used to evaluate the antioxidant activity of methanolic extract of leaves of $C$. papaya.

Results: The methanolic leaf extract of $C$. papaya showed antioxidant property with free radical scavenging activity increasing with increase in concentration. The IC50 value of methanolic extract was $213.68 \mu \mathrm{gm} / \mathrm{ml}$. Ascorbic acid was used as control.

Conclusions: Oxidative stress has been linked to heart disease, cancer, immune deficiency. Antioxidants as suggested from various studies may reduce the risk of such diseases. The utility of $C$. papaya in the treatment of heart disease, cancer and immune deficiency will have to be proved by detailed evaluation of its pharmacological properties.
\end{abstract}

Keywords: Carica papaya, Antioxidant activity, $\mathrm{DPPH}, \mathrm{IC}_{50}$

\section{INTRODUCTION}

Since ancient times Indians have been known to employ various parts of plants of medicinal value to cure different diseases. ${ }^{1}$ The many types of forests spread out across India are estimated to contain $90 \%$ of India's medicinal plants while the rest $10 \%$ are found in nonforest areas. ${ }^{2}$

Due to the various adverse effects associated with synthetic drugs, the modern medicinal research is now focusing with renewed interest on medicinal plants. ${ }^{3}$ Many medicinal plants are a major source of drug discovery since they may also contain secondary metabolites having pharmacological activity. These secondary metabolites may also play a large role in plant defence mechanism. They are however unlikely to be involved in growth and reproduction. The results of many studies have shown their role in antioxidants, anti-cancer, anti-inflammatory and pain relieving properties. ${ }^{4}$

Carica papaya (C. papaya) is a member of the family of Caricaceae. Many species of Caricaceae have been used in the treatment of various ailments. ${ }^{5}$ Papaya plant is grown in tropics and subtropics among varied countries like India, Brazil, Indonesia, Mexico and Nigeria with India being the largest producer of papaya. In the Indian context the leaves have been used for colic, fever, beriberi, abortion, and asthma. Besides, papaya leaves have also been traditionally used in the treatment of 
jaundice, malaria, dengue. ${ }^{6,7}$ The dried leaves are taken as tonic for blood purification. Papaya leaf tea is used to treat obesity for bringing down weight and is also effective against chronic indigestion, high blood pressure and arteriosclerotic weakening of heart. ${ }^{8}$ Active compounds such as papain, chymopapain, cystatin, tocopherol, ascorbic acid, flavonoids, cyanogenic glucosides and glucosinolates are able to display antioxidant activity and reduce lipid peroxidation and have been shown to be present in papaya leaves. ${ }^{9}$

The consumption of antioxidant rich foods help in neutralizing the free radical in the body. It will prevent and delay the oxidative damage of lipids, proteins and nucleic acids. ${ }^{10}$ The therapeutic effect of medicinal plants are also due to the presence of phytochemical compounds. Various studies involving phytochemical analysis of papaya leaves have reported the presence of alkaloids, glycosides, saponins, flavonoids, phenolics, proteins and amino acids. Leaves of $C$. papaya also contain carbohydrates, minerals, vitamins, lipids and proteins and so can also be used as a nutritional agent in addition to being used as a medicinal agent. ${ }^{11-15}$ Besides, two studies conducted by Halim et al and Afzan et al have assessed the acute and sub-acute oral toxicity of papaya leaf extract on Sprague Dawley rats. Acute administration of high dose of C. papaya leaf extract did not produce any acute adverse effects or death. ${ }^{16,17}$

\section{METHODS}

\section{Collection of plant material}

Fresh leaves of $C$. papaya were collected from the campus of GMC Thrissur in the month of November. The collected plant leaves were washed with tap water and rinsed with distilled water to remove dust particles and then the leaves were shade dried and made into a fine powder with an electric grinder. The powdered sample was sealed in polythene bags and stored in desiccators.

\section{Preparation of methanolic extract}

Dried and powdered leaves (100 g) were used. The extract was prepared using Soxhlet apparatus with $300 \mathrm{ml}$ of methanol for about $16 \mathrm{~h}$. The crude plant extract in solvent was removed from the Soxhlet and concentrated to dryness in rotary vacuum evaporator below $50^{\circ} \mathrm{C}$ and stored in refrigerator.

\section{Phytochemical screening}

Phytochemical screening using standard tests was done.

Test for alkaloids (Dragendorff's reagent test): $1 \mathrm{ml}$ of the extract and $1 \mathrm{ml}$ of reagent (potassium bismuth iodide).

Orange red precipitate obtained.
Test for flavanoids (Shinoda test): $1 \mathrm{ml}$ of the extract with four magnesium ribbons and 2 drops of concentrated hydrochloric acid.

Reddish color obtained.

Test for glycosides (picric acid test): To1 $\mathrm{ml}$ of the extract was added $1 \mathrm{ml}$ picric acid followed by $0.5 \mathrm{ml}$ of $10 \%$ sodium carbonate.

Appearance of reddish colour indicated the presence of glycosides.

Test for saponins (foam test): To $1 \mathrm{ml}$ of the extract was added $2 \mathrm{ml}$ of distilled water and shaken thoroughly.

Formation of white stable foam indicated the presence of saponins.

Test for tannins: To $1 \mathrm{ml}$ of the extract 2-3 drops of $\mathrm{FeCl}_{3}$ solution was added.

Greenish black precipitate indicated the presence of tannins.

Test for carbohydrate: $1 \mathrm{ml}$ of extract was added to $5 \mathrm{ml}$ of Benedict's reagent and the solution was heated for 2 minutes.

Greenish colour indicated the presence of carbohydrates.

\section{Scavenging of DPPH}

The radical scavenging activity of methanolic leaf extracts was determined on the basis of the radical scavenging effect on the DPPH. In brief, $0.1 \mathrm{mM}$ solution of DPPH in methanol was prepared. This solution $(1 \mathrm{ml})$ was added to $3 \mathrm{ml}$. of different concentration of extracts in methanol. After vigorous shaking the mixture was allowed to stand at room temperature for $30 \mathrm{~min}$. Using spectrophotometer the absorbance was measured at 517 $\mathrm{nm}$. Lower absorbance of the reaction mixture indicated higher free radical scavenging activity. The tests were all done in triplicate.

The percentage DPPH scavenging effect was calculated by using the following equation.

DPPH scavenging effect $(\%)$ or percent inhibition=

A0-A1/A0×100.

Where $\mathrm{A} 0$ is the absorbance of control reaction and $\mathrm{A} 1$ is the absorbance in presence of test or standard sample.

The percentage of inhibition was plotted against concentration and from the graph IC50 was calculated. The IC50 is defined as the concentration of substrate that causes $50 \%$ loss of the DPPH activity (colour). 
The values have been taken as the average of three experiments and are shown as mean $(n=3)$

\section{Statistical analysis}

The results are expressed as mean value $(n=3)$. The dose response relationship of the extract was derived using regression analysis.

\section{RESULTS}

The results of phytochemical screening of $C$. papaya leaves by various tests conducted showed the presence of alkaloids, flavonoids, glycosides, saponins, tannins and carbohydrates (Table 1).

Table 1: Phytochemical screening of methanolic extract of $C$. papaya leaf.

\begin{tabular}{|l|l|}
\hline $\begin{array}{l}\text { Phytochemical } \\
\text { constituent }\end{array}$ & $\begin{array}{l}\text { Methanolic extract of } \\
\text { C. papaya }\end{array}$ \\
\hline Alkaloid & Present \\
\hline Flavonoids & Present \\
\hline Glycoside & Present \\
\hline Saponin & Present \\
\hline Tannin & Present \\
\hline Carbohydrate & Present \\
\hline
\end{tabular}

Table 2: Inhibition of methanolic leaf extract of $C$. papaya at various concentrations.

\begin{tabular}{|ll|}
\hline Concentration $(\mu \mathrm{g} / \mathrm{ml})$ & Inhibition $(\%)$ \\
\hline $\mathbf{5 0 . 5 6}$ & 15.31 \\
\hline $\mathbf{1 0 1 . 1 3}$ & 27.19 \\
\hline $\mathbf{2 0 2 . 2 5}$ & 47.55 \\
\hline
\end{tabular}

Values - mean of three measurements.

The radical scavenging effect on DPPH was used as the basis to determine the free radical scavenging activity of methanolic leaf extract of papaya. DPPH has the advantage of being unaffected by certain side reactions, such as metal ion chelation and enzyme inhibition brought about by various additives, which is a feature distinctive from laboratory generated free radicals such as the hydroxyl radical and superoxide anion which can be affected by side reactions. A freshly prepared DPPH solution is of a deep purple colour which generally changes to yellow when an antioxidant is present in the medium. Antioxidant molecules react with DPPH resulting in the scavenging of the free radical by hydrogen donation. When the DPPH radical is scavenged, there is a decrease in its absorbance at wavelength $517 \mathrm{~nm}$. Methanolic extracts of papaya leaf showed antioxidant activity comparable to standard ascorbic acid at varying concentrations. All the concentrations tested showed a dose dependent increase in the percentage antioxidant activity. In each concentration, the tests were performed in triplicate and the mean $\pm \mathrm{SD}$ of the three tests were taken.
The percentage inhibition of methanolic leaf extract of $C$. papaya at various concentrations $(\mu \mathrm{gm} / \mathrm{ml})$ in $\mathrm{DPPH}$ scavenging model revealed that increasing concentrations of $C$. papaya show a linear increase in antioxidant activity. The antioxidant activity at each concentration is $15.31,27.19$ and 47.55 which are the mean value $(n=3)$ (Table 2).

Similarly, the percentage inhibition at various concentrations of the standard, proven antioxidant, ascorbic acid, also showed a linear increase in antioxidant activity. The antioxidant activity at each concentration is $48.46,73.26$ and 91.18 which are the mean value $(n=3)$ (Table 3).

Table 3: Inhibition of standard ascorbic acid at various concentrations.

\begin{tabular}{|ll|}
\hline Concentration $(\mu \mathrm{g} / \mathrm{ml})$ & Inhibition $(\%)$ \\
\hline $\mathbf{1}$ & 48.46 \\
\hline $\mathbf{2}$ & 73.26 \\
\hline
\end{tabular}

Values - mean of three measurements

Table 4: IC50 values of methanolic leaf extract of $C$. papaya and ascorbic acid.

\begin{tabular}{|ll|}
\hline $\begin{array}{l}\text { Preparation } \\
\text { Methanolic leaf extract } \\
\text { of } \boldsymbol{C} \text {. papaya }\end{array}$ & 213.68 \\
\hline Ascorbic acid & 1.02 \\
\hline
\end{tabular}

The $\mathrm{IC}_{50}$ value of methanolic leaf extract of $C$. papaya by DPPH method was obtained as $213.68 \mu \mathrm{g} / \mathrm{ml}$ and that of ascorbic acid was obtained as $1.02 \mu \mathrm{g} / \mathrm{ml}$ (Table 4 ).

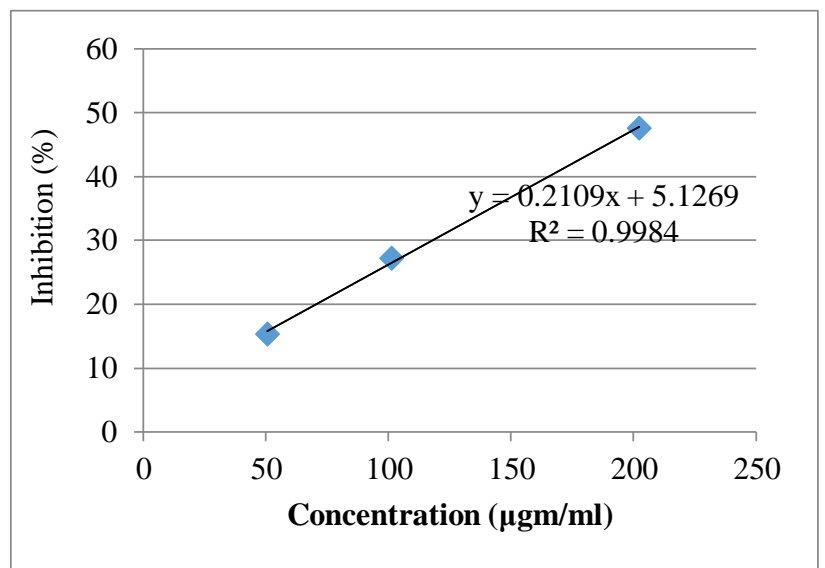

Figure 1: DPPH free radical scavenging activity of methanolic leaf extract of $C$. papaya.

By plotting different concentrations against percentage (\%) inhibition, a straight-line graph is obtained. $\mathrm{R}^{2}$ is the coefficient of regression (Figure 1 and 2). 


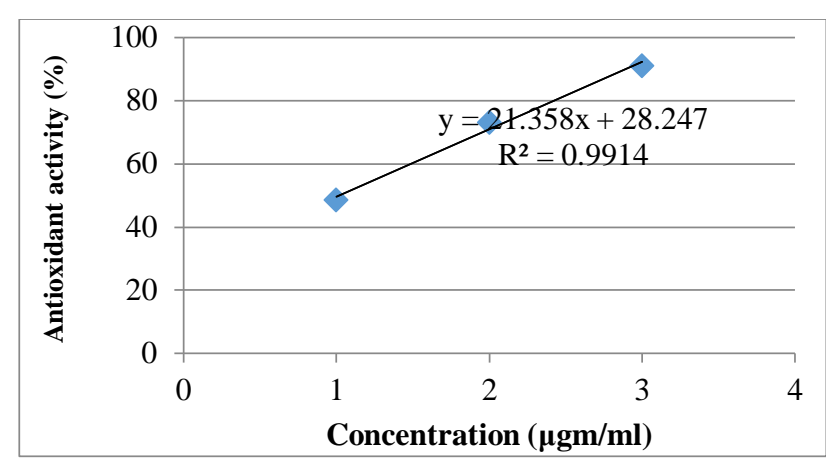

Figure 2: DPPH free radical scavenging activity of standard ascorbic acid.

\section{DISCUSSION}

DPPH free radical scavenging assay is one of the most frequently used assays as it is advantageous compared to other laboratory generated free radicals and is accurate. ${ }^{18}$ The present study shows that $C$. papaya has good demonstrable antioxidant activity. The present study is comparable to the study conducted by Banu et al which showed antioxidant activity of papaya leaves as determined by DPPH method. ${ }^{19}$ Similarly, a study by Mandal et al, again employing DPPH assay also showed that $C$. papaya leaves have potent antioxidant power. ${ }^{20}$

Free radicals have been implicated in the pathogenesis of a wide range of diseases from atherosclerosis, ischemic heart disease and cancer to Alzheimer's disease and Parkinson's disease. ${ }^{21}$ Antioxidants may protect the body against free radicles by scavenging the reactive metabolites or by converting them to less reactive molecules. ${ }^{22}$ Sagadevan et al in their study on methanolic and ethanolic papaya leaf extract have demonstrated the antioxidant activity of papaya leaves from nitric oxide scavenging assay and hydroxyl radical scavenging assay. ${ }^{23}$ Additionally, a study conducted by Saini et al has also demonstrated the antioxidant property of $C$. papaya fruit too. ${ }^{24}$

\section{CONCLUSION}

The preliminary phytochemical investigations done on the methanolic extract of $C$. papaya leaf have confirmed the presence of biologically active compounds. This study has also revealed the presence of significant antioxidant property for the methanolic leaf extract of C. papaya which presents an easily available source of natural antioxidants for common use. The antioxidant properties may be the contribution of various bioactive components. Further studies need to be carried out to exactly identify, isolate and possibly quantify the actual components responsible for the antioxidant activity.

Funding: No funding sources

Conflict of interest: None declared

Ethical approval: The study was approved by the Institutional Ethics Committee

\section{REFERENCES}

1. Swammy SMK, Tan BKH. Cytotoxic and Immunopotentiating Effects of Ethanolic Extracts of Nigella Sativa L. Seeds. J Ethnopharmacol. 2000;70(1):1-7.

2. Ilanchezhian RC, Roshy J, Acharya R. Importance of Media in Shodhana (Purification Processing) of Poisonous Herbal Drugs. Anc Sci of Life. 2010;30(2):54-7.

3. Roshan A, Verma NK, Gupta A. A Brief Study on Carica papaya - A Review. Int J Current Trends Pharma Res. 2014;2(4):541-50.

4. Dias DA, Urban S, Roessner U. A Historical Overview of Natural Products in Drug Discovery. Metabolites. 2012;2(2):303-36.

5. Mello VJ, Gomes MT, Leos FO, Delfino JL, Andrade SP, Lopes MT, et al. The Gastric Ulcer Protective and Healing Role of Cysteine Proteinases from Carica Candamarcensis. Phytomedicine. 2008;15(4):237-44.

6. Bergonio KB, Perez MA. The Potential of Male Papaya (Carica papaya L.) Flower as a Functional Ingredient for Herbal Tea Production. Indian J Traditional Knowledge. 2016;15(1):41-49.

7. Kavimandan B, Saraf M. Studies on Biological Efficacy of Various Leaf Extracts of Carica papaya L. Int Conference Global Trends Engineering, Tech Manag. 2016: 510-516.

8. Nugroho A, Heryani H, Choi JS, Park HJ. Identification and Quantification of Flavonoids in Carica papaya Leaf and Peroxynitrite-scavenging Activity. Asian Pacific J Tropical Biomede. 2017;7(3):208-13.

9. Seigler DS, Pauli GF, Nahrstedt A, Leen R. Cyanogenic Allosides and Glucosides from Passiflora Edulis and Carica papaya. Phytochemistry. 2002;60(8):873-82.

10. Lim YY, Lim TT, Tee JJ. Antioxidant Properties of Several Tropical Fruits: A Comparative Study. Food Chem. 2007;103(3):1003-8.

11. Corral-Aguayo RD, Yahia EM, Carrillo-López A, González-Aguilar G. Correlation Between Some Nutritional Components and the Total Antioxidant Capacity Measured with Six Different Assays in Eight Horticultural Crops. J Agri Food Chem. 2008;56(22):10498-504.

12. Okeniyi JA, Ogunlesi TA, Oyelami OA, Adeyemi LA. Effectiveness of Dried Carica papaya Seeds Against Human Intestinal Parasitosis: A pilot study. J Med Food. 2007;10(1):194-6.

13. Eleazu CO, Eleazu KC, Awa E, Chukwuma SC. Comparative Study of the Phytochemical Composition of the Leaves of Five Nigerian Medicinal Plants. E3 J Biotech Pharma Res. 2012;3(2):42-6.

14. Imaga NA, Gbenle GO, Okochi VI, Adenekan S, Duro-Emmanuel T, Oyeniyi B, et al. Phytochemical and Antioxidant Nutrient Constituents of Carica 
papaya and Parquetina Nigrescens Extracts. Scientific Res Essays. 2010;5(16):2201-5.

15. Ayoola PB, Adeyeye A. Phytochemical and Nutrient Evaluation of Carica papaya (Pawpaw) Leaves. Int J Recent Res Applied Studies. 2010;5(3):325-28.

16. Halim SZ, Abdullah NR, Afzan A, Rashid BA, Jantan I, Ismail Z. Acute Toxicity Study of Carica papaya Leaf Extract in Sprague Dawley rats. J Med Plants Res. 2011;5(10):1867-72.

17. Afzan A, Abdullah NR, Halim SZ, Rashid BA, Hazlini R, Semail R et al. Repeated Dose 28-Days Oral Toxicity Study of Carica papaya L. Leaf Extract in Sprague Dawley Rats. Molecules. 2012;17(4):4326-42.

18. Sangeetha M, Venkatalakshmi P. In Vitro Antioxidant Activity of the Aqueous Extract of Andrographis Paniculata and Carica papaya Leaves. World J Pharm Pharm Sci. 2017;6(5):1631-43.

19. Sahira BK, Cathrine L. Antioxidant Activity of Carica papaya Leaf Extract (Rajasthan Variety). Int J Res Applied Sci Engineering Techn. 2018;6(3):225963.

20. Surajit DM, Lalmawizuala R, Vabeiryureilai $M$, Nachimuthu SK, Esther L. An Investigation of the Antioxidant Property of Carica papaya Leaf Extracts from Mizoram, Northeast India. Res Rev: J Botanical Sci. 2015;4(2):43-6.

21. Stanner A, Hughers J, Kelly CN, Buttriss J. Review of the Epidemiological Evidence for the Antioxidant Hypotheses. Public Health Nutrition. 2004;7(3):40722.

22. Hegde K, Joshi AB. Hepatoprotective Effect of Carissa Carandas Linn Root Extract Against CCl4 and Paracetamol Induced Hepatic Oxidative Stress. Ind J Exp Biol. 2009;47:660-7.

23. Sagadevan P, Jayaramjayaraj K. In Vitro Antioxidant, Anticancer Activity of Acetone and Methanol Extracts of Carica papaya. International $\mathbf{J}$ Pharma Bio Sci. 2018;9(2):B6-16.

24. Ritu S, Aman M, Vaibhav R. Formulation \& in-vitro Antioxidant Analysis of Anti-ageing Cream of Carica papaya Fruit Extract. Indian $\mathrm{J}$ Drugs. 2016;4(1):8-14.

Cite this article as: Aboobacker HK, Valoth G, Kizhedath S. In vitro study on the antioxidant activity of methanolic leaf extract of Carica papaya. Int J Basic Clin Pharmacol 2020;9:652-6. 